\title{
EXPLORING GAME PERFORMANCE IN NBA PLAYOFFS
}

\author{
Nuno Mateus ${ }^{1}$, Bruno Gonçalves ${ }^{1}$, Eduardo Abade ${ }^{2}$, Nuno Leite ${ }^{1}$, \\ Miguel Angel Gomez ${ }^{3}$, and Jaime Sampaio ${ }^{1}$ \\ ${ }^{1}$ Research Center in Sports Sciences, Health Sciences and Human Development, CIDESD, \\ CreativeLab Research Community, Portugal \\ ${ }^{2}$ Research Center in Sports Sciences, Health Sciences and Human Development, CIDESD, \\ CreativeLab Research Community, University Institute of Maia, ISMAI, Portugal \\ ${ }^{3}$ Faculty of Physical Activity and Sport Sciences, Polytechnic University of Madrid, Spain
}

Original scientific paper

https://doi.org/10.26582/k.50.1.7

UDC: $796.323 .2: 796.071 .2$

\begin{abstract}
:
This study aimed to identify performance profiles in NBA playoffs and describe performances in the first and the last games of the series. Thirty games from the official box-scores and player-tracking data of the 2014/15 NBA playoffs were considered. A k-means cluster analysis was performed to group the players according to their game performance profiles and a discriminant analysis was conducted to identify the game-related statistics that best discriminated the groups. The first function correctly classified $64.2 \%$ of the cases and the second function classified $29.9 \%$ of the cases. The cluster analysis identified four different performance profiles and from the discriminant analysis emerged several offensive and defensive variables to classify the players in the clusters. The identified trends help to improve understanding of the game during different stages of playoffs. Coaches may use this information to better prepare their teams for different game scenarios.
\end{abstract}

Key words: game statistics, players profile, discriminant analysis

\section{Introduction}

The National Basketball Association (NBA) is consensually considered the most popular and competitive basketball league in the world. The competition is organized into two conferences and six divisions, with a regular season comprising 82 games for each team. The conferences' top eight teams compete for the championship in a playoff system (available at http://www.nba.com/). This competition system exposes players to a highlycongested schedule that directly affects their performance. Therefore, the multifactorial performance determinants of basketball players in the NBA are highly influenced by the contextual variables related to the game type (Gómez, Lago, \& Pollard, 2013), game location (Ibáñez, et al., 2008), physiological stress, travels and accumulated fatigue (Gonzalez, et al., 2013). These factors should be monitored by technical staffs during the season's planning for a fine-tune evaluation of their performance.

Another significant variable that may also affect players' performance is the game importance (Baumeister, 1984). From a psychological approach, the game importance seems determinant when players are exposed to higher pressure, partly because their performance may drop due to the increased stress over their actions, such as in a deciding playoff game. In fact, performance under pressure is mediated by several factors that may have an effect on players' mind-set, such as leading or losing a series in a potential decisive game or playing in front of supportive audiences (Tauer, Guenther, \& Rozek, 2009). This inherent pressure of decisive moments tends to increase self-awareness and conscious attention, which may lead to performance decrements (Beilock \& Gray, 2007; Wallace, Baumeister, \& Vohs, 2005). Under this scope, game-related statistics have been used to evaluate technical and tactical behaviours within different sporting contexts in basketball (Sampaio, et al., 2015), and are considered relevant when predicting the game outcome (Percy, 2015). For example, playoffs phase increases the probability of close contested games to occur, with fouls and free-throws exhibiting increased significance for defining the game outcome (Sampaio \& Janeira, 2003). Despite changes in players' performance along a playoff series, this topic is quite unexplored by current literature.

Although a series potential deciding game may have a significant impact on players' behav- 
iour (Tauer, et al., 2009), it is unclear which indicators best discriminate performance ups and downs during these moments and, consequently, which players perform better under these circumstances. For that reason it is important to understand how players use information provided by the competitive environment (Davids, Araujo, Correia, \& Vilar, 2013), but it is also imperative to know which players use it better to improve their assertiveness and decision making, mainly in decisive games. Under this scope, the data gathered during a competition may highlight important predictors that can be used to discriminate players into different performance groups. From a methodological perspective, the cluster analysis has been extensively used within this principle. This classification technique may be useful to establish and compare performance profiles, according to some variables, such as players' importance (Sampaio, et al., 2015), team quality (Sampaio, Drinkwater, \& Leite, 2010), or playing time (Mateus, et al., 2015). It also can provide important information on how the players behave and deal with different circumstances in the game, particularly during playoff games.

The use of game-performance statistics to monitor players' performance during a game has been widely explored, mainly during regular season periods (Gomez, Gasperi, \& Lupo, 2016; Ibáñez, et al., 2008). However, the fact is that playoff games have unique characteristics that require players to deal with circumstances rarely experienced during the first competition phase of the season (García, Ibáñez, Santos, Leite, \& Sampaio, 2013; Sampaio \& Janeira, 2003). Taking the above-mentioned issues into consideration, this study aimed to identify different performance profiles in NBA playoffs and describe differences in performance in the first and the last game of the series.

\section{Methods}

\section{Sample of subjects and variables}

Archival data were obtained from the openaccess official NBA box-scores and player-tracking of the 2014/2015 playoffs (available at http://stats. nba.com). The competition was carried out in a bestof-seven elimination tournament among 16 teams, where only the best eight teams of each Conference (East and West) participated. This comprises the first-round, conference semi-finals, conference finals and NBA final playoffs. A total of 30 games was considered in order to analyse only the first and the last game of each series. The first game represents teams within same statuses in the beginning of the series; it is of high importance to start winning the series and to keep the home-court advantage along the next games. The last game is critical and decisive since one or both teams face the elimination; it presents unpredictable contexts in which the teams may show a non-equilibrium state where each behaviour and action may modify the game state and then the final outcome with one team facing the elimination (Gomez, et al., 2016). No games have been excluded, regardless the game outcome or the occurrence of additional periods. The gamerelated statistics gathered were: field-goals (2-point, 3 -point, contested, uncontested, and defended at rim) made and attempted, free-throws made and attempted, assists (assists, secondary assists, and free-throw assists), touches, passes made, rebounds (offensive, offensive rebounds chances, defensive, and defensive rebounds chances), steals, blocks, turnovers, personal fouls, average speed and distance covered. The source used for gathering these variables is reliable as stated by Gomez et al. (2016) and Sampaio et al. (2015). In addition, a sub-sample of five games were re-analysed by two experienced analysts and the results of inter-rater reliability were high (kappa coefficients $>.90$ ) in all game statistics. Physical parameters could not be reassessed due to limitations of the video footage provided by the SportsVU company (Northbrook, IL, USA).

\section{Procedure and statistical analysis}

The considered variables of the first and the last game from all playoff series were screened for univariate outliers (cases outside the range of Mean \pm 3 SD) and data distribution was tested, together with advised assumptions for each following inferential analysis (Pedhazur, 1982). In order to compare the game-related statistics collected among the groups, the variables were normalized according to every player's playing time, resulting in derived-rate variables. A k-means cluster analysis was performed with the aim of creating and describing maximally different groups of game performance profiles using the variables from both games. The cubic clustering criterion, together with Monte Carlo simulations, was used to identify the optimal number of clusters, thereby avoiding using subjective criteria. This statistical technique requires that all cases have no missing values in any of the variables introduced in the model. Afterwards, to identify which variables best discriminate the previously obtained clusters, a descriptive discriminant analysis was conducted. The structure coefficients greater than $|0.30|$ were interpreted as meaningful contributors to the discrimination between the groups (Pedhazur, 1982). Validation of discriminant models was conducted using the leave-one-out method of cross-validation (Norušis, 2006). Descriptive analysis was performed to all variables $(\mathrm{M} \pm \mathrm{SD})$ according to the obtained clusters. Statistical significance was set at $\mathrm{p}=.05$ and calculations were performed using JMP statistics software package (release 11.0, SAS Institute, Cary, NC, USA) and SPSS software (IBM SPSS Statistics for Windows, Version 22.0. Armonk, NY: IBM Corp.). 


\section{Results}

The cluster analysis allowed us to create four different groups of game-performance profiles. The means and standard deviations from the game-related variables according to the clusters are presented in Table 1 (includes: field-goals, 3-point field-goals and free-throws' statistics) and Table 2 (contains other performance indicators gathered for the study).

Cluster 1 incorporated players with the worst overall performance values in both the first and the last game of the series. The players from cluster 2 presented the best values in almost all offensive game-statistics, especially in shooting and passing variables. In these players also the differences between the first and the last game of the series were displayed. Cluster 3 gathered players who stood out in rebounds, blocks and field-goals defended at rim. These players showed differences in field-goals made, free-throws and assists between the first and the final game of the series. The players from cluster 4 performed closer to cluster 2 players in some shooting variables, especially in 3-point field-goals (made and attempted) and in uncontested field-goals (made and attempted), in both the first and the last game of the series.
The tables also presented the structure coefficients from the functions that allow discriminating of the groups. The structure coefficients from the first function ( $\%$ of variance explained $=64.2)$ reflected a stronger emphasis on touches $\left(\mathrm{SC}_{\text {first-game }}=0.605\right.$, $\left.\mathrm{SC}_{\text {last-game }}=0.601\right)$, and a smaller but equally important emphasis on passes made $\left(\mathrm{SC}_{\text {first-game }}=0.498\right.$, $\left.\mathrm{SC}_{\text {last-game }}=0.495\right)$ and field-goals attempted $\left(\mathrm{SC}_{\text {first- }}\right.$ game $=0.484, \mathrm{SC}_{\text {last-game }}=0.489$ ), in both the first and the last game of the series. This function also emphasized distance run, but only in the last game of the playoff series $\left(\mathrm{SC}_{\text {last-game }}=0.455\right)$. The second function $(\%$ of variance explained $=26.9)$ is highlighted by "without-ball" actions, such as rebounds (offensive rebounds [ $\left.\mathrm{SC}_{\text {first-game }}=0.498\right]$ and offensive $\left[\mathrm{SC}_{\text {first-game }}=0.475\right]$ and defensive $\left[\mathrm{SC}_{\text {first-game }}=0.422\right]$ rebound chances) and field-goals defended at rim attempted $\left(\mathrm{SC}_{\text {first-game }}=0.479\right)$, particularly in the first game of the playoff series.

Complementarily, Figure 1a presents a territorial map from the cases and created clusters within the space from the first and second discriminant functions. The cluster 2 players had better performances in the variables related to function 1 , while the players from cluster 3 had better performances in the variables related to function 2 . Figures $1 \mathrm{~b}$

Table 1. Means, standard deviations and structure coefficients from the obtained model of clusters

\begin{tabular}{|c|c|c|c|c|c|c|c|}
\hline \multicolumn{2}{|c|}{ Cluster/Variable } & \multirow{2}{*}{$\begin{array}{c}\text { Cluster } 1 \\
1.5 \pm 1.4\end{array}$} & \multirow{2}{*}{$\begin{array}{c}\text { Cluster } 2 \\
8.5 \pm 3.3\end{array}$} & \multirow{2}{*}{$\begin{array}{c}\text { Cluster } 3 \\
4.7 \pm 2.8\end{array}$} & \multirow{2}{*}{$\begin{array}{c}\text { Cluster } 4 \\
4.4 \pm 2.1\end{array}$} & \multirow{2}{*}{$\begin{array}{c}\begin{array}{c}\text { Function } 1 \\
(64.2 \%)\end{array} \\
0.430^{*}\end{array}$} & \multirow{2}{*}{$\begin{array}{c}\begin{array}{c}\text { Function } 2 \\
(26.9 \%)\end{array} \\
-0.054\end{array}$} \\
\hline \multirow{16}{*}{$\begin{array}{l}\frac{0}{01} \\
0 \\
\frac{1}{1} \\
\frac{1}{0} \\
\frac{0}{4}\end{array}$} & Made - First game & & & & & & \\
\hline & Made - Last game & $1.3 \pm 1.3$ & $8.0 \pm 2.7$ & $5.4 \pm 2.4$ & $4.0 \pm 2.7$ & $0.418^{*}$ & 0.067 \\
\hline & Attempted - First game & $3.7 \pm 2.8$ & $18.9 \pm 5.6$ & $10.4 \pm 6.1$ & $10.1 \pm 3.9$ & $0.484^{*}$ & -0.078 \\
\hline & Attempted - Last game & $3.6 \pm 2.8$ & $18.2 \pm 5.4$ & $10.6 \pm 5.0$ & $9.6 \pm 4.3$ & $0.489^{*}$ & -0.037 \\
\hline & Contested Made - First game & $0.8 \pm 1.1$ & $4.9 \pm 2.4$ & $3.5 \pm 2.1$ & $2.1 \pm 1.7$ & $0.342^{*}$ & 0.105 \\
\hline & Contested Made - Last game & $0.8 \pm 1.1$ & $4.3 \pm 2.2$ & $3.8 \pm 2.1$ & $1.8 \pm 1.7$ & $0.317^{*}$ & 0.218 \\
\hline & Contested Attempted - First game & $2.0 \pm 2.2$ & $10.7 \pm 4.1$ & $7.2 \pm 3.9$ & $4.9 \pm 3.1$ & $0.393^{*}$ & 0.077 \\
\hline & Contested Attempted - Last game & $2.0 \pm 2.0$ & $9.6 \pm 3.9$ & $7.2 \pm 3.8$ & $4.4 \pm 2.8$ & $0.375^{*}$ & 0.139 \\
\hline & Uncontested Made b - First game & $0.6 \pm 0.8$ & $3.6 \pm 2.0$ & $1.2 \pm 1.6$ & $2.3 \pm 1.5$ & $0.272^{*}$ & -0.214 \\
\hline & Uncontested Made b - Last game & $0.6 \pm 0.7$ & $3.7 \pm 2.1$ & $1.6 \pm 1.6$ & $2.2 \pm 1.8$ & $0.278^{*}$ & -0.137 \\
\hline & Uncontested Attempted b - First game & $1.7 \pm 1.5$ & $8.2 \pm 3.4$ & $3.3 \pm 3.2$ & $5.2 \pm 2.5$ & $0.339^{*}$ & -0.229 \\
\hline & Uncontested Attempted b - Last game & $1.6 \pm 1.5$ & $8.6 \pm 3.5$ & $3.4 \pm 2.8$ & $5.2 \pm 2.7$ & $0.367^{*}$ & -0.223 \\
\hline & Defended at Rim Made - First game & $1.0 \pm 1.3$ & $1.7 \pm 1.6$ & $4.0 \pm 2.5$ & $1.4 \pm 1.5$ & 0.118 & $0.375^{*}$ \\
\hline & Defended at Rim Made - Last game & $1.0 \pm 1.1$ & $1.6 \pm 1.7$ & $3.1 \pm 2.3$ & $1.2 \pm 1.2$ & 0.109 & $0.302^{*}$ \\
\hline & Defended at Rim Attempted - First game & $1.9 \pm 2.3$ & $3.3 \pm 2.3$ & $7.7 \pm 3.8$ & $2.5 \pm 2.0$ & 0.146 & $0.479^{*}$ \\
\hline & Defended at Rim Attempted - Last game & $1.8 \pm 2.1$ & $3.1 \pm 3.2$ & $6.4 \pm 3.9$ & $2.2 \pm 2.1$ & 0.124 & $0.363^{*}$ \\
\hline \multirow{4}{*}{ 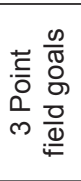 } & Made - First game & $0.3 \pm 0.6$ & $1.6 \pm 1.6$ & $0.2 \pm 0.5$ & $1.7 \pm 1.5$ & 0.153 & -0.295 \\
\hline & Made - Last game & $0.2 \pm 0.5$ & $2.1 \pm 1.9$ & $0.2 \pm 0.6$ & $1.5 \pm 1.5$ & 0.198 & $-0.257^{*}$ \\
\hline & Attempted - First game & $1.0 \pm 1.4$ & $4.9 \pm 2.9$ & $1.0 \pm 1.4$ & $4.3 \pm 2.8$ & 0.220 & -0.339 \\
\hline & Attempted - Last game & $1.0 \pm 1.5$ & $5.8 \pm 3.4$ & $1.0 \pm 2.0$ & $4.1 \pm 2.6$ & 0.259 & $-0.340^{*}$ \\
\hline \multirow{4}{*}{ 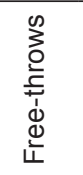 } & Made - First game & $0.6 \pm 1.1$ & $4.6 \pm 3.2$ & $2.3 \pm 2.0$ & $1.7 \pm 1.9$ & $0.281^{*}$ & -0.015 \\
\hline & Made - Last game & $0.6 \pm 1.2$ & $4.8 \pm 4.1$ & $3.4 \pm 2.2$ & $1.5 \pm 1.6$ & $0.284^{*}$ & 0.129 \\
\hline & Attempted - First game & $0.9 \pm 1.5$ & $5.9 \pm 3.7$ & $3.6 \pm 3.1$ & $2.3 \pm 2.2$ & $0.282^{*}$ & 0.051 \\
\hline & Attempted - Last game & $0.9 \pm 1.5$ & $5.9 \pm 4.7$ & $5.2 \pm 3.1$ & $2.0 \pm 2.2$ & $0.283^{*}$ & 0.205 \\
\hline
\end{tabular}

Legend: $\mathrm{b}$ - variables not entering the canonical discriminant analysis model. ${ }^{*} p<.05$ 
Table 2. Means, standard deviations and structure coefficients from the obtained model of clusters

\begin{tabular}{|c|c|c|c|c|c|c|}
\hline Cluster/Variable & Cluster 1 & Cluster 2 & Cluster 3 & Cluster 4 & $\begin{array}{c}\text { Function } 1 \\
(64.2 \%)\end{array}$ & $\begin{array}{c}\text { Function } 2 \\
(26.9 \%)\end{array}$ \\
\hline Assists - First game & $0.8 \pm 1.1$ & $6.4 \pm 3.1$ & $2.4 \pm 2.4$ & $2.5 \pm 1.7$ & $0.376^{*}$ & -0.118 \\
\hline Assists - Last game & $0.8 \pm 1.1$ & $6.6 \pm 3.0$ & $1.6 \pm 1.6$ & $2.5 \pm 2.2$ & $0.372^{*}$ & -0.222 \\
\hline Secondary Assists - First game & $0.3 \pm 0.6$ & $1.3 \pm 1.1$ & $0.8 \pm 0.9$ & $0.8 \pm 1.0$ & $0.163^{*}$ & -0.014 \\
\hline Secondary Assists - Last game & $0.2 \pm 0.6$ & $1.3 \pm 1.2$ & $0.6 \pm 0.7$ & $0.5 \pm 0.8$ & $0.175^{*}$ & -0.024 \\
\hline Free Throw Assists - First game & $0.0 \pm 0.2$ & $0.6 \pm 0.7$ & $0.1 \pm 0.4$ & $0.3 \pm 0.6$ & 0.134 & $-0.138^{*}$ \\
\hline Free Throw Assists - Last game & $0.1 \pm 0.2$ & $0.8 \pm 1.0$ & $0.3 \pm 0.6$ & $0.3 \pm 0.5$ & $0.177^{*}$ & -0.037 \\
\hline Touches - First game & $20.1 \pm 12.3$ & $87.1 \pm 15.9$ & $52.8 \pm 19.6$ & $47.0 \pm 15.3$ & $0.605^{*}$ & -0.030 \\
\hline Touches - Last game & $20.4 \pm 15.0$ & $88.9 \pm 19.0$ & $53.8 \pm 16.9$ & $44.1 \pm 14.0$ & $0.601^{*}$ & 0.005 \\
\hline Passes Made - First game & $14.8 \pm 9.5$ & $59.1 \pm 14.0$ & $37.9 \pm 15.4$ & $32.7 \pm 12.6$ & $0.498^{*}$ & 0.003 \\
\hline Passes Made - Last game & $15.4 \pm 12.1$ & $60.6 \pm 14.4$ & $38.4 \pm 14.0$ & $30.8 \pm 11.5$ & $0.495^{*}$ & 0.026 \\
\hline Offensive Rebounds - First game & $0.8 \pm 1.1$ & $1.0 \pm 1.2$ & $3.3 \pm 2.0$ & $0.7 \pm 0.8$ & 0.095 & $0.498^{*}$ \\
\hline Offensive Rebounds - Last game & $0.7 \pm 1.1$ & $1.2 \pm 1.2$ & $2.6 \pm 1.7$ & $0.7 \pm 1.0$ & 0.104 & $0.346^{*}$ \\
\hline OR Chances - First game & $1.6 \pm 1.9$ & $2.1 \pm 1.7$ & $5.7 \pm 3.0$ & $1.6 \pm 1.5$ & 0.103 & $0.475^{*}$ \\
\hline OR Chances - Last game & $1.4 \pm 1.6$ & $2.2 \pm 2.1$ & $4.5 \pm 3.0$ & $1.4 \pm 1.7$ & 0.102 & $0.352^{*}$ \\
\hline Defensive Rebounds - First game & $1.7 \pm 1.7$ & $5.3 \pm 3.1$ & $6.8 \pm 2.2$ & $3.4 \pm 2.4$ & 0.275 & $0.333^{*}$ \\
\hline Defensive Rebounds - Last game & $1.6 \pm 1.7$ & $5.8 \pm 3.5$ & $6.9 \pm 3.5$ & $3.5 \pm 2.4$ & 0.274 & $0.288^{*}$ \\
\hline DR Chances - First game & $2.9 \pm 2.4$ & $7.8 \pm 3.7$ & $11.0 \pm 3.5$ & $5.2 \pm 3.3$ & 0.291 & $0.422^{*}$ \\
\hline DR Chances - Last game & $2.7 \pm 2.5$ & $8.1 \pm 3.8$ & $10.6 \pm 4.6$ & $5.2 \pm 3.2$ & 0.279 & $0.349^{*}$ \\
\hline Steals - First game & $0.4 \pm 0.7$ & $1.8 \pm 1.2$ & $0.7 \pm 0.8$ & $1.0 \pm 1.1$ & $0.186^{*}$ & -0.110 \\
\hline Steals - Last game & $0.3 \pm 0.6$ & $1.6 \pm 1.4$ & $0.8 \pm 1.2$ & $0.7 \pm 1.0$ & $0.182^{*}$ & -0.021 \\
\hline Blocks - First game & $0.2 \pm 0.6$ & $0.6 \pm 1.0$ & $1.4 \pm 1.5$ & $0.4 \pm 0.6$ & 0.094 & $0.278^{*}$ \\
\hline Blocks - Last game & $0.3 \pm 0.6$ & $0.7 \pm 1.0$ & $1.1 \pm 1.3$ & $0.5 \pm 0.9$ & 0.090 & $0.147^{*}$ \\
\hline Turnovers - First game & $0.6 \pm 0.8$ & $3.0 \pm 1.9$ & $1.7 \pm 1.5$ & $1.5 \pm 1.4$ & $0.255^{*}$ & -0.022 \\
\hline Turnovers - Last game & $0.4 \pm 0.7$ & $3.4 \pm 2.6$ & $1.8 \pm 1.3$ & $1.3 \pm 1.2$ & $0.300^{*}$ & 0.010 \\
\hline Personal Fouls - First game & $1.5 \pm 1.3$ & $2.4 \pm 1.5$ & $2.9 \pm 1.4$ & $2.4 \pm 1.4$ & 0.125 & 0.094 \\
\hline Personal Fouls - Last game & $1.6 \pm 1.5$ & $2.8 \pm 1.5$ & $3.0 \pm 1.7$ & $2.5 \pm 1.5$ & 0.127 & 0.076 \\
\hline Average Speed - First game & $4.3 \pm 0.7$ & $4.0 \pm 0.3$ & $4.0 \pm 0.2$ & $4.2 \pm 0.3$ & $-0.086^{*}$ & -0.067 \\
\hline Average Speed - Last game & $4.2 \pm 0.7$ & $4.0 \pm 0.2$ & $4.0 \pm 0.2$ & $4.2 \pm 0.3$ & -0.046 & -0.064 \\
\hline Distance Run - First game & $0.9 \pm 0.5$ & $2.6 \pm 0.3$ & $2.1 \pm 0.5$ & $2.1 \pm 0.5$ & 0.515 & 0.017 \\
\hline Distance Run - Last game & $0.9 \pm 0.6$ & $2.6 \pm 0.4$ & $2.2 \pm 0.4$ & $2.0 \pm 0.6$ & $0.455^{*}$ & 0.064 \\
\hline
\end{tabular}
${ }^{*} \mathrm{p}<.05$

(a) All players

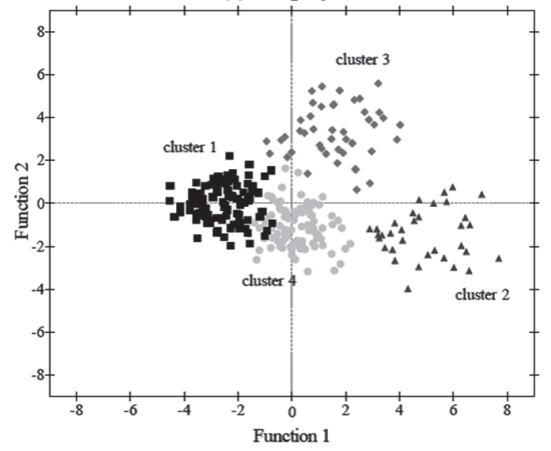

(b) Final winners

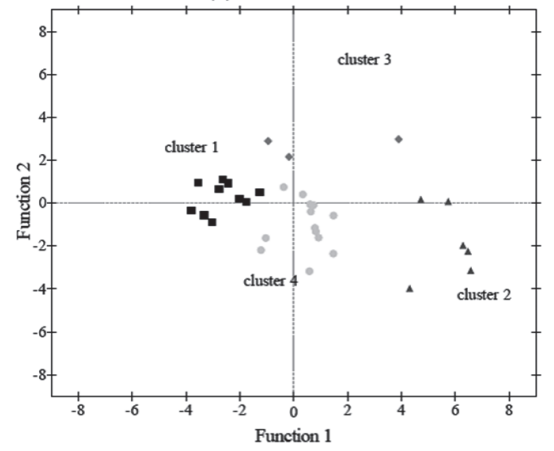

(c) 1st round losers

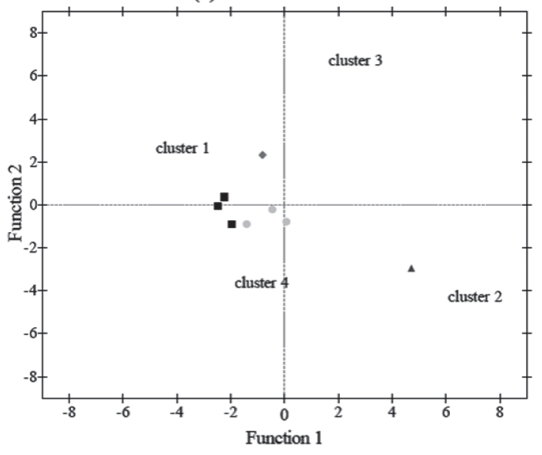

Figure 1. Territorial map from the cases and created clusters: (a) all teams; (b) the final winners; and (c) first round losers of playoffs.

and 1c present the profile of eight players who had higher playing time for the champion team and for the team eliminated in the first round, respectively. Figure $1 \mathrm{~b}$ has a higher number of cases because it includes records of eight games (i.e., from the first round to the final game), while Figure 1c only contemplates two games (i.e., the first and the last game from the first round). It seems that winners 
have a balanced representation in all clusters, as opposed to the players of the first-round losing team that are mostly allocated to clusters 1 and 4 .

\section{Discussion and conclusions}

This study aimed to identify how the basketball game-related variables from the first and the last game of the NBA playoffs series contributed to the development of different performance profiles. Differences in NBA players' performances were identified, as well as the game related-statistics that best discriminate performance profiles in competition.

\section{Describing different game performance profiles}

The cluster analysis identified four different groups of players according to their game performance. The groups differed from each other in offensive and defensive game statistics, although discrepancies in some physical variables were also observed.

Cluster 1 players presented a lower association with most of the variables, which may be related to their less important role on the teams, as reported in Sampaio and colleagues (2010). In fact, if we examine game statistics of both games, these players had lower average values in almost all variables (except for offensive rebounds chances and average speed) when compared to the players classified in the other clusters. Interestingly, these players covered less distances, but exhibited higher average speed values regardless of the game. It may be speculated that lower distances covered were a consequence of less playing time being the result of their poorer performance (Sampaio, Drinkwater, et al., 2010; Sampaio \& Janeira, 2003). According to Sampaio and others (2015), higher average speed values could be a result of players' bad decisions of when and where to run in offense and defence, which required from Cluster 1 players to run faster in order to correct their position on the court. These results showed that even in crucial moments of the season, where only the best teams compete, there is space for players with clearly poor performance.

The players from cluster 2 performed better in the function 1 variables. Since this function is mainly saturated with offensive actions, we can predict that players integrated in this cluster had great importance in the offensive organizational and scoring processes of their teams, like guards or small forwards (Mateus, et al., 2015; Sampaio, Janeira, Ibáñez, \& Lorenzo, 2006; Sampaio, et al., 2015). Coaching staffs should consider this information, especially if they want to overtake the strengths of the opponents, since game statistics show that these players stand out considerably from the others in field-goals made and attempted, freethrows made, touches, assists, passes made and turn- overs. This performance profile is typical of players with higher offensive propensity (Sampaio, Ibañez Godoy, Gómez Ruano, Lorenzo Calvo, \& Ortega Toro, 2008; Sampaio, et al., 2015). These trends have also been noticed by Fewell, Armbruster, Ingraham, Petersen, and Waters (2012), who suggest that NBA teams use a playmaker to centralise ball distribution during ball possessions.

The players from cluster 3 had good performance in the actions of both functions, nonetheless they had a greater affinity with the second function variables. Despite of their offensive importance, these players particularly stood out in defensive processes of their teams, presenting a greater emphasis on no ball actions (rebounds, blocks, field goals defended at rim), which might be synonymous with greater physical and combat capacity (Sampaio, Drinkwater, et al., 2010; Sampaio, et al., 2006). Offensively, the players presented important free-throws values, a typical outcome of excessive contacts during a shot and in offensive rebounds variable. Moreover, these players presented lower values in the variables related to the three-point field-goals, which may indicate that they perform near to the basket (Sampaio, et al., 2006). In defence game statistics, these players differed from the other clusters in the following indicators: defensive rebounds, defensive rebound chances, field goals defended at rim and blocks. This is in accordance with the previously mentioned characteristics of these players - they are powerful men who perform especially without the ball and preferentially in the paint (Sampaio, et al., 2006). In fact, current NBA centers tend to be less technically prepared and more specialised in physical and defensive actions close to the paint zone without the ball (Erčulj \& Štrumbelj, 2015). This is key information for coaches, since it reveals that during playoffs players with this performance profile can play an important role on both sides of the court.

The players in cluster 4 had a greater affinity with the function 1. Despite playing less time and not being the main offensive "threats" (cluster 2 players showed a greater correlation with the first function variables and presented higher frequency of offensive actions), these players appear to be important in the offensive phase, particularly when shooting (3-point field-goals and uncontested field goals made), which may be a strong indicator of their outside shooting ability (García, et al., 2013). These results reinforce the offensive collective behaviour of NBA teams depicted by Fewell et al. (2012), since passing sequences are strongly focused on open situations for shooter specialists, such as shooting-guards or power-forwards (Fewell, et al., 2012).

In addition, there is a clear contrast in the number of players from different clusters between the winning team and the first-round losers. Inter- 
estingly, the players from the losing teams are mostly allocated in the clusters with low or less dominant performances (clusters 1 and 4). Moreover, the first-round loser team only presents one player in cluster 3, which asserts the idea that the NBA worst ranked-teams have difficulties in achieving good performances close to the rim (Courel-Ibáñez, McRobert, Toro, \& Vélez, 2016). Conversely, although the final winners had a high concentration of players in cluster 4 , they were also widely represented in cluster 2 , which demonstrates their greater importance and offensive value.

\section{Comparing performances between the first and the last game of a playoff series}

The presented game statistics show that the players performed differently between the first and the last game of the playoff series. However, differences were not as significant as expected. Furthermore, it did not exist a uniform relation between the groups, because not all players presented a break or an increase at the same game statistics. The results of the present study clearly show that: a) most of the players took more shots in the first game of the series; b) there is a greater tendency to resort to certain players in the last game of the series; c) there is a greater tendency to execute, take outside shots in the last game of the series; d) in the last game, players performed more passes and revealed a higher number of ball touches; and e) in the last game, players performed more fouls and achieved a greater performance in some defensive actions (e.g., defensive rebounds).

Under pressure, some players tend to take fewer shots to the basket (Wallace, Caudill, \& Mixon, 2013). Therefore, with the exception of cluster 3 , players shot more in the first game of the playoff series. A decrease in the number of field-goals may be due to higher psychological pressure associated to the last game, which is considered a decisive game (Swartz, Tennakoon, Nathoo, Tsao, \& Sarohia, 2011). As previously mentioned, cluster 3 players have a greater emphasis on actions closer to the basket, which indicates that they act preferably near to the basket as center players. Since they are the ones in whom an increase in the number of field-goals made and field-goals attempted occurs between the first and the last game, our results suggest that in playoffs, when pressure increases (last game), there is a tendency to recourse to players with these characteristics. Perhaps because teams look for easier and more effective strategies to achieve points (Gomez, et al., 2016). This issue becomes even more evident when we compare the variables of free-throws of the first and the last game - these players presented a higher average in the deciding game, synonymous with attacking the basket and having the ball in their possession more frequently. They also performed fewer assists in the last game, which highlights the importance of shooting the ball instead of passing it at a highlevel competition. According to Courel-Ibáñez et al. (2016), the inside-pass may be a functional collective strategy to using the athleticism of taller inside players, since NBA teams that execute this type of action during offense, tend to enhance inside shooting options and effectiveness.

In the last game of the playoff series, players appeared to prefer shooting from outside the paint, maybe because defences became more consistent and tougher, thus impairing chances of penetrating or playing one-on-one (Gomez, et al., 2010). Additionally, some players resent in the most important games, betting less on individual actions, played in a cooperative way (Sampaio, et al., 2010) thus avoiding risky options, perhaps because they felt the greater importance of the last game. Between the first and the last game of the playoffs players tended to play more collectively (performing fewer shots and more passes), penetrated less to the basket (the increased number of three-point field-goals and fewer contested field-goals), teams favoured the ball rotation between their players in order to destabilize defence and enable, create open shots without opposition (an increase in the number of passes and touches on the ball) (Gómez, Tsamourtzis, \& Lorenzo, 2006). In fact, this could be an efficient solution since consecutive performance of several offensive actions, such as inside passes (CourelIbáñez, et al., 2016) and ball-screens (Gómez, et al., 2015) with different players involved, lead to a defensive imbalance (Lamas, Santana, Heiner, Ugrinowitsch, \& Fellingham, 2015), which enables promising scoring situations inside the paint and opportunities to assist open teammates. This trend is evident in most of the players, but mainly in cluster 2 ones who excelled in the first function variables (field-goals made, field-goals attempted, assists, passes and touches), but from the first to the last game, both the field-goals made and attempted diminished and they executed fewer contested fieldgoals. On the other hand, they performed more three-point field goals made and attempted, passed the ball more frequently and executed more assists.

The idea that in the last game defences become more conservative in order to preclude easy shots and provide less space for opposing players to play one-on-one situations is also present. This is more evident in personal fouls, which is the only uniform variable among the groups, because all clusters present an increase in personal fouls from the first to the last game. The larger number of personal fouls can be interpreted as a greater defensive attitude and aggressiveness. Besides that, it can also be an indicator of strategies to constrain and stop offensive processes of opposing teams or even to force less skilled players to go to the free-throw line (Bar-Eli \& Tractinsky, 2000; Kenter, 2015). The values found in the defensive rebounds support the 
hypothesis that in the last game defences became more cohesive, because there was an increase in the number of defensive rebounds in almost all groups. This cohesion and teamwork seem to force the opposing team to shoot hastily (García, et al., 2013; Trninić, Dizdar, \& Lukšić, 2002). Consequently, the defending teams secure more easily defensive rebounds, preventing offensive rebounds and potential second shots from the opposite teams (Trninić, et al., 2002). However, it is necessary to account for players' fatigue that increases throughout the game (Abdelkrim, et al., 2010). Collectively, team defence begins to be slower and more dispersed (Sampaio, Gonçalves, Rentero, Abrantes, \& Leite, 2014); this is the reason why the final quarter of a game may represent a critical moment for defences and a key opportunity for offenses.

This study provides information about different stages of playoffs. Different groupings were identified based on players' performance, particularly in relation to organizational, scoring and without-theball game-statistics. It was found that most players took shots more frequently in the first game of the series, possibly due to a greater psychological load associated with the last game. In the decisive game there was a greater tendency to taking perimeter shots, to perform more passes and touches of the ball, probably because defences became more cohesive and closed, giving less space to penetrate or to play one-on-one, and forcing the players to shoot outside the three-point line. So, offences favoured the ball rotation to destabilize defences and looked for certain players, with the intention of attempting less risky shots, preferably without the opposition. Also in the last game, players committed more fouls and achieved a greater performance in some defensive actions. Probably, defensive players became more aggressive and displayed more attitude and effort to preclude opponents' unopposed shots, the second ball possessions or easy baskets. Thus, coaches should design specific training programs to prepare - psychologically and technically players for this moments, considering their individuality and role on the team, and develop special tactics according to the game changes that occur throughout playoffs series.

\section{References}

Abdelkrim, N.B., Castagna, C., Jabri, I., Battikh, T., El Fazaa, S., \& El Ati, J. (2010). Activity profile and physiological requirements of junior elite basketball players in relation to aerobic-anaerobic fitness. Journal of Strength and Conditioning Research, 24(9), 2330-2342.

Bar-Eli, M., \& Tractinsky, N. (2000). Criticality of game situations and decision making in basketball: An application of performance crisis perspective. Psychology of Sport and Exercise, 1(1), 27-39.

Baumeister, R.F. (1984). Choking under pressure: Self-consciousness and paradoxical effects of incentives on skillful performance. Journal of Personality and Social Psychology, 46(3), 610.

Beilock, S.L., \& Gray, R. (2007). Why do athletes choke under pressure? In G. Tenenbaum \& B. Eklund (Eds.), Handbook of sport psychology, $3^{\text {rd }}$ ed. (pp. 425-444). New Jersey: John Wiley \& Sons.

Courel-Ibáñez, J., McRobert, A.P., Toro, E.O., \& Vélez, D.C. (2016). Inside pass predicts ball possession effectiveness in NBA basketball. International Journal of Performance Analysis in Sport, 16(2), 711-725.

Davids, K., Araujo, D., Correia, V., \& Vilar, L. (2013). How small-sided and conditioned games enhance acquisition of movement and decision-making skills. Exercise and Sports Science Review, 41(3), 154-161.

Erčulj, F., \& Štrumbelj, E. (2015). Basketball shot types and shot success in different levels of competitive basketball. PLoS ONE, 10(6), e0128885.

Fewell, J.H., Armbruster, D., Ingraham, J., Petersen, A., \& Waters, J.S. (2012). Basketball teams as strategic networks. PLoS ONE, 7(11), e47445.

García, J., Ibáñez, S.J., Santos, R.M.D., Leite, N., \& Sampaio, J. (2013). Identifying basketball performance indicators in regular season and playoff games. Journal of Human Kinetics, 36, 163-170.

Gómez, Á., Tsamourtzis, E., \& Lorenzo, A. (2006). Defensive systems in basketball ball possessions. International Journal of Performance Analysis in Sport, 6(1), 98-107.

Gómez, M.-Á., Battaglia, O., Lorenzo, A., Lorenzo, J., Jiménez, S., \& Sampaio, J. (2015). Effectiveness during ball screens in elite basketball games. Journal of Sports Sciences, 33(17), 1844-1852.

Gomez, M.A., Gasperi, L., \& Lupo, C. (2016). Performance analysis of game dynamics during the 4th game quarter of NBA close games. International Journal of Performance Analysis in Sport, 16(1), 249-263.

Gómez, M., Lago, C., \& Pollard, R. (2013). Situational variables. In T. McGarry, P. O’ Donoghue \& J. Sampaio (Eds.), Routledge handbook of sports performance analysis (pp. 259-269). London: Routledge.

Gomez, M., Lorenzo, A., Ibanez, S.J., Ortega, E., Leite, N., \& Sampaio, J. (2010). An analysis of defensive strategies used by home and away basketball teams. Perceptual and Motor Skills, 110(1), 159-166.

Gonzalez, A.M., Hoffman, J.R., Rogowski, J.P., Burgos, W., Manalo, E., Weise, K., Fragala, M.S., Stout, J.R. (2013). Performance changes in NBA basketball players vary in starters vs. nonstarters over a competitive season. Journal of Strength and Conditioning Research, 27(3), 611-615. 
Ibáñez, S.J., Sampaio, J., Feu, S., Lorenzo, A., Gómez, M.A., \& Ortega, E. (2008). Basketball game-related statistics that discriminate between teams' season-long success. European Journal of Sport Science, 8(6), 369-372.

Kenter, F.H. (2015). An analysis of the basketball endgame: When to foul when trailing and leading. In 9th MIT Sloan Sports Analytics Conference.

Lamas, L., Santana, F., Heiner, M., Ugrinowitsch, C., \& Fellingham, G. (2015). Modeling the offensive-defensive interaction and resulting outcomes in basketball. PLOS ONE, 10(12), e0144435.

Mateus, N., Gonçalves, B., Abade, E., Liu, H., Torres-Ronda, L., Leite, N., \& Sampaio, J. (2015). Game-to-game variability of technical and physical performance in NBA players. International Journal of Performance Analysis in Sport, 15, 764-776.

Norušis, M.J. (2006). SPSS 14.0 guide to data analysis. Upper Saddle River, NJ: Prentice Hall.

Pedhazur, E. (1982). Multiple regression in behavioral research: Explanation and prediction. New York: Holt, Rinehart and Winston.

Percy, D.F. (2015). Strategy selection and outcome prediction in sport using dynamic learning for stochastic processes. Journal of the Operational Research Society, 66(11), 1840-1849.

Sampaio, J., Drinkwater, E.J., \& Leite, N.M. (2010). Effects of season period, team quality, and playing time on basketball players' game-related statistics. European Journal of Sport Science, 10(2), 141-149.

Sampaio, J., Gonçalves, B., Rentero, L., Abrantes, C., \& Leite, N. (2014). Exploring how basketball players' tactical performances can be affected by activity workload. Science and Sports, 29(4), e23-e30.

Sampaio, J., Ibañez Godoy, S.J., Gómez Ruano, M.Á., Lorenzo Calvo, A., \& Ortega Toro, E. (2008). Game location influences basketball players performance across playing positions. International Journal of Sport Psychology, 39(3), 43-50.

Sampaio, J., \& Janeira, M. (2003). Statistical analyses of basketball team performance: Understanding teams' wins and losses according to a different index of ball possessions. International Journal of Performance Analysis in Sport, 3, 40-49.

Sampaio, J., Janeira, M., Ibáñez, S., \& Lorenzo, A. (2006). Discriminant analysis of game-related statistics between basketball guards, forwards and centres in three professional leagues. European Journal of Sport Science, 6, 173-178.

Sampaio, J., Lago, C., \& Drinkwater, E.J. (2010). Explanations for the United States of America's dominance in basketball at the Beijing Olympic Games (2008). Journal of Sports Sciences, 28(2), 147-152.

Sampaio, J., McGarry, T., Calleja-González, J., Sáiz, S.J., Alcázar, X.S. i. d., \& Balciunas, M. (2015). Exploring game performance in the National Basketball Association using player tracking data. PLoS ONE, 10(7), e0132894.

Swartz, T.B., Tennakoon, A., Nathoo, F., Tsao, M., \& Sarohia, P. (2011). Ups and downs: Team performance in bestof-seven playoff series. Journal of Quantitative Analysis in Sports, 7(4), 1559-0410.

Tauer, J.M., Guenther, C.L., \& Rozek, C. (2009). Is there a home choke in decisive playoff basketball games? Journal of Applied Sport Psychology, 21(2), 148-162. doi: 10.1080/10413200902795331

Trninić, S., Dizdar, D., \& Lukšić, E. (2002). Differences between winning and defeated top quality basketball teams in final tournaments of European club championship. Collegium Antropologicum, 26(2), 521-531.

Wallace, H.M., Baumeister, R.F., \& Vohs, K.D. (2005). Audience support and choking under pressure: A home disadvantage? Journal of Sports Sciences, 23(4), 429-438.

Wallace, S., Caudill, S.B., \& Mixon Jr., F.G.M. (2013). Homo certus in professional basketball? Empirical evidence from the 2011 NBA Playoffs. Applied Economics Letters, 20, 642-648.

Submitted: October 25, 2016

Accepted: May 30, 2017

Published Online First: January 16, 2018

Correspondence to:

Nuno Mateus, Ph.D. student

Research Center in Sports Sciences, Health Sciences

and Human Development, CIDESD, CreativeLab

Research Community, Portugal

Quinta de Prados, Ap. 202, 5000-911 Vila Real,

Portugal

Phone: +351968175576

E-mail: nuno_mateus23@hotmail.com

\section{Acknowledgement}

This study was conducted under the Project NanoSTIMA: Macro-to-Nano Human Sensing: Towards Integrated Multimodal Health Monitoring and Analytics/NORTE-01-0145-FEDER-000016, which is financed by the North Portugal Regional Operational Programme (NORTE 2020), under the PORTUGAL 2020 Partnership Agreement, and through the European Regional Development Fund (ERDF). 